Article

\title{
Synthesis of Bisphenol A Based Phosphazene-Containing Epoxy Resin with Reduced Viscosity
}

Vyacheslav V. Kireev ${ }^{1}$, Yulya V. Bilichenko ${ }^{1}$, Roman S. Borisov ${ }^{2,3}$, Jianxin Mu ${ }^{4}$, Dmitry A. Kuznetsov ${ }^{5}$, Anastasiya V. Eroshenko ${ }^{1}$, Sergey N. Filatov ${ }^{1}$ and Igor S. Sirotin $1, *$ (D)

1 Department of Plastics, Mendeleev University of Chemical Technology of Russia, Miusskaya sq. 9, 125047 Moscow, Russia; kireev@muctr.ru (V.V.K.); julyab2@gmail.com (Y.V.B.); eroshenko.nast@yandex.ru (A.V.E.); filatovsn@muctr.ru (S.N.F.)

2 Topchiev Institute of Petrochemical Synthesis, Russian Academy of Sciences, Leninskii pr. 29, 119991 Moscow, Russia; borisov@ips.ac.ru

3 Department of Organic Chemistry, Peoples' Friendship University of Russia, Miklukho-Maklaya str.6, 117198 Moscow, Russia

4 College of Chemistry, Jilin University, 2699 Qianjin Street, Changchun 130012, China; emujianxin@163.com

5 Scientific \& Research Institute of Natural Gases and Gas Technologies-Gazprom VNIIGAZ, Razvilka, s.p. Razvilkovskoe, Leninsky dist., Moscow region, 142717 Moscow, Russia; expdk@yandex.ru

* Correspondence: isirotin@muctr.ru; Tel.: +7-(499)-978-9265

Received: 3 October 2019; Accepted: 16 November 2019; Published: 20 November 2019

\begin{abstract}
Phosphazene-containing epoxy oligomers (PEO) were synthesized by the interaction of hexachlorocyclotriphosphazene (HCP), phenol, and bisphenol A in a medium of excess of epichlorohydrin using potassium carbonate and hydroxide as $\mathrm{HCl}$ acceptors with the aim of obtaining a product with lower viscosity and higher phosphazene content. PEOs are mixtures of epoxycyclophosphazene (ECP) and a conventional organic epoxy resin based on bisphenol A in an amount controlled by the ratio of the initial mono- and diphenol. According to ${ }^{31} \mathrm{P}$ NMR spectroscopy, pentasubstituted aryloxycyclotrophosphazene compounds predominate in the ECP composition. The relative content in the ECP radicals of mono- and diphenol was determined by the MALDI-TOF mass spectrometry method. The organic epoxy fraction, according to gas chromatograpy-mass spectrometry (GC-MS), contains $50-70 \mathrm{wt} \%$ diglycidyl ether of bisphenol A. PEO resins obtained in the present work have reduced viscosity when compared to other known phosphazene-containging epoxy resins while phosphazene content is still about $50 \mathrm{wt} \%$. Resins with an epoxy number within $12-17 \mathrm{wt} \%$, are cured by conventional curing agents to form compositions with flame-retardant properties, while other characteristics of these compositions are at the level of conventional epoxy materials.
\end{abstract}

Keywords: epoxy resin; epoxy oligomer; phosphazene; bisphenol A; phenol

\section{Introduction}

Out of all the varieties of synthetic polymers, epoxies, developed over 70 years ago, won a special place in industry and everyday life, not necessarily in terms of overall manufacturing volume, moreso in their specific role [1]. Classic bisphenol A based epoxy resins have many advantages: low cost, low curing shrinkage, good chemical resistance, and mechanical properties [1,2]. In terms of valuable qualities, epoxy polymers are superior to many other classes of synthetic polymers, which makes them indispensable as a basis for adhesives, paints, coatings, and binders for reinforced plastics $[1,3]$. The development and application of new epoxy oligomers and binders based on them are expanding at a rapid pace despite the appearance of new generation binders, such as bismaleimides, polyimides, 
and cyanate esters [2]. The latter are characterized by enhanced physical and mechanical properties, including high heat resistance and low flammability. However, their price is very high, their processing properties are worse than those of the same epoxides, and a high degree of crosslinking can adversely affect the mechanical properties [1,2].

However, polymers based on unmodified epoxy resins often have low and unstable performance characteristics, in particular flammability and relatively low heat resistance [3].

A rather effective way to increase the heat resistance of epoxy matrices is with structural modification, for example, with compatible oligomers of higher functionality, which are incorporated into the three-dimensional network structure formed during curing. Examples of such resins are triglycidyl-p-aminophenol (TGPAP), tetraglycidyl-4, $4^{\prime}$-methylenedianiline (TGMDA), and epoxidized novolacs [3,4].

The solution of the flammability problems of epoxy polymers is a more complex issue and involves trade-offs. Thus, a traditional and effective way to reduce the flammability of epoxy systems is to replace bisphenol A based epoxy resins with their brominated analogs. However, brominated epoxy resins, as well as other halogen-containing compounds, emit toxic gases when they come into contact with flames, which limits their use, for example, in civil aviation and transport, for environmental reasons $[5,6]$.

One of the promising ways of modifying epoxy polymers to increase heat and fire resistance is the introduction of organometallic compounds, in particular phosphorus compounds, known as universal flame retardants for a large number of polymeric materials. Refusal of halogen-containing flame retardants in favor of phosphorus-based ones is a modern global trend [5].

However, the introduction of low-molecular, non-reactive compounds into the material, including red phosphorus and its inorganic compounds (phosphates, polyphosphates, etc.) worsens the mechanical properties and transparency of polymers [5]. Organic phosphates, which are better combined with the base polymer, have proven themselves more functional. Meanwhile, there are some difficulties associated, for example, with the fact that ethers of phosphoric acids can act as plasticizers, reducing the heat resistance of the material [7]. The best properties are possessed by binders containing functional organic phosphorus compounds capable of forming covalent bonds with an epoxy matrix. [6,8]. For example, glycidyl ethers of phosphorus acids, which not only reduce the flammability, but also increase the mechanical and adhesive strength of the material, are quite promising structural phosphorus-containing modifiers [8,9]. However, they are also poorly compatible with epoxy polymers $[9,10]$. Finally, most industrial phosphorus-containing flame retardants have a much lower degradation temperature than epoxy polymers $[5,6,11,12]$, which makes it impossible to use them in engineering plastics and as part of high-temperature binders.

The combination of the above factors leads to the fact that epoxy resins are not always able to satisfy the growing needs of high-tech industries, especially in the aerospace industry, automotive industry, electrical engineering, electronics, etc.

A possible way to solve the problems described above, including the flammability of epoxy resins, is the use of modifiers based on phosphazenes.

The main chain of organophosphazenes consists of alternating atoms of phosphorus and nitrogen, and at the phosphorus atom there are organic radicals introduced by the substitution of halogen in halogenphosphazenes. The nature of organic substituents, usually introduced by the reaction of nucleophilic substitution of chlorine, can vary widely and determines the properties of the final polymer or oligomer. The unique properties of various organophosphazenes cause the ever-growing interest of researchers in phosphazene chemistry [13]. Compared to other organophosphorus compounds, aryloxyphosphazenes have, as a rule, higher thermal stability and chemical resistance and are promising non-halogen flame-retardants $[6,14,15]$, characterized by the synergistic action of phosphorus and nitrogen $[14,16]$. Thus, phenoxycyclophosphazenes were commercialized as a flame retardant by Otsuka Chemical and others [14,17].

Researchers have long been trying to combine the exceptional properties of organophosphazenes as highly effective flame retardants with the function of structural modifiers, such as polyfunctional 
epoxy resins. There are two main synthetic approaches that allow to obtain functional phosphazenes capable of forming covalent bonds with epoxy matrices:

(1) The synthesis of organophosphazenes with reactive epoxy groups for addition to the epoxy component [18-43];

(2) The synthesis of organophosphazenes with reactive amine groups for use as a curing agent or its component [44-52].

Functional epoxyphosphazenes are highly effective flame retardants that not only do not reduce mechanical properties, since they are well compatible with the epoxy matrix, but can also improve them, probably due to the formation of a special three-dimensional polymer network, in the nodes of which phosphazene cycles are located [53].

Currently, the majority of methods for the synthesis of functional epoxyphosphazenes described in the literature are of primarily scientific interest due to the complexity of scaling and the large number of intermediate stages [18-22,24,28,30,31,33-36,38-43]. Although there are epoxyphosphazenes that are fairly easy to synthesize, for example, on the basis of hexachlorocyclo triphosphazene and glycidol [23, 25-27,29,32,37,40]. However, alkoxyphosphazenes, which include such glycidyloxyphosphazenes, are not thermally stable [13]. Thus, even during their synthesis, an undesirable phosphazene-phosphazane rearrangement occurs [27]. Thus, only aromatic organophosphazenes can be used as a component of high-temperature epoxy binders.

In recent years, phosphazene-containing epoxy oligomers (PEO) with reduced flammability on the base of cyclic chlorophosphazenes have been synthesized and characterized [54]. The most accessible and promising are PEOs obtained by the reaction of epichlorohydrin with hydroxyaryloxycyclotriphosphazenes (HAP), the condensation products of hexachlorocyclotriphosphazene (HCP) and 4,4'-dioxydiphenyl-2,2propane (Figure 1).

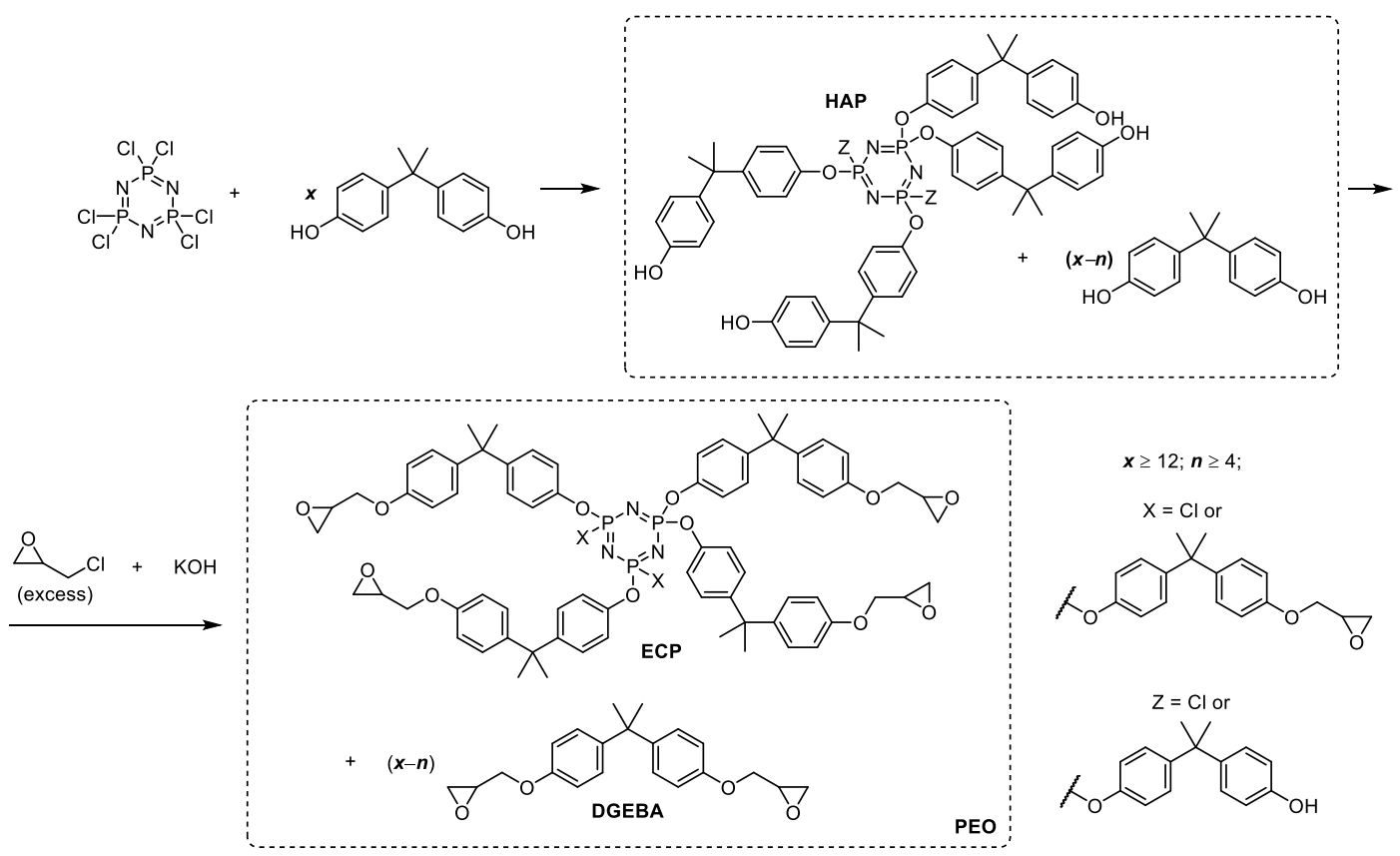

Figure 1. Synthesis of phosphazene-containing epoxy oligomers by the reaction of epichlorohydrin with hydroxyaryloxycyclotriphosphazenes, the condensation products of hexachlorocyclotriphosphazene and 4,4'-dioxydiphenyl-2,2-propane [55]. Hydroxyaryloxycyclotriphosphazenes (HAP), epoxycyclophosphazene (ECP), diglycidyl ether of bisphenol A (DGEBA), phosphazene-containing epoxy oligomers (PEO).

The main problem in the synthesis of $\mathrm{PEO}$ is the high functionality of $\mathrm{HCP}$, which requires the use of a more than 10-fold molar excess of diphenol to achieve a more complete replacement of the chlorine 
atoms in it and to avoid gelation. As for the industrial use of epoxyphosphazenes, the main limiting factor complicating the preparation of the formulation and worsening its processing properties is that most epoxyphosphazenes are solids with a softening temperature of $80-100^{\circ} \mathrm{C}$ and high melt viscosity. High average functionality can also influence processing properties.

Epoxidation of a mixture of HAP and excess of diphenol with epichlorohydrin produces PEO, which contains fractions of the usual bisphenol A based epoxy resin and epoxycyclophosphazene (ECP) oligomers with a variable ratio [54]. In [55,56], single-stage synthesis of PEO was realized by direct interaction of HCP and an excess of diphenol (bisphenol A [55,56] or resorcinol [57]) in the epichlorohydrin medium as a reagent and a solvent. The resulting PEO includes ECP consisting essentially of tetra- and pentaepoxides of the above formula with $n=4$ and 5 and a conventional organic epoxy monomer. These PEOs in comparison with pure epoxyphosphazenes contain organic epoxide, which is in fact an active diluent that lowers the viscosity and average functionality to an acceptable level for further processing. However, the viscosity of such PEO concentrates at ambient temperature is still more than $200 \mathrm{~Pa} \cdot \mathrm{s}$, which is a fairly high value, close to the processing limit.

The content of ECP in a mixture with the organic epoxide may be increased with simultaneous reducing of the content of residual chlorine, the functionality of HCP and its molecular weight, which was realized in our previous work [53] by replacing part of the chlorine atoms in chlorophosphazene with monophenol residues (Figure 2).

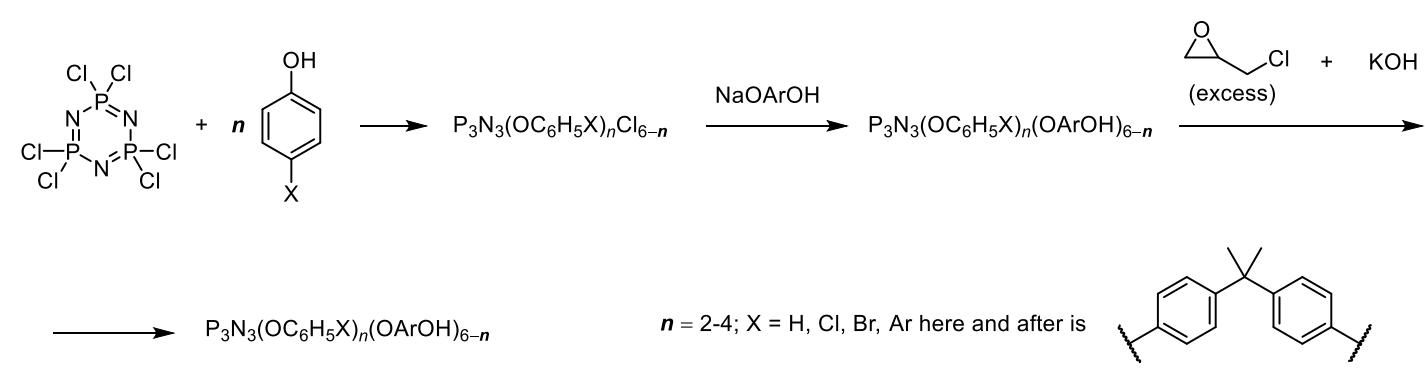

Figure 2. Replacement of the part of the chlorine atoms in chlorophosphazene with monophenol residues in order to increase the content of epoxycyclophosphazenes in a mixture with the organic epoxide [53].

According to matrix-assisted laser desorption/ionization time-of-flight MALDI-TOF mass spectrometry, the main components of the oligomer formed are phosphazene-containing di-, triand tetraepoxides, the ratio of which in the reaction mixture can be varied by alternation of the value of $n$. The average content of epoxy groups in these PEO is $13 \%-14 \%$ by weight. Compositions based on diglycidyl ether of bisphenol A (DGEBA) and methyltetrahydrophthalic anhydride, containing $15 \%$ of the obtained oligomers in the epoxy component, compared to pure DGEBA, were characterized by more than $30 \%$ higher glass transition temperature and flexural strength, and at $75 \%$ content of PEO were non-combustible and had limiting oxygen index (LOI) of 30 [53]. However, the need to obtain and use of phenolates complicates the scalability of the described method.

Thus, the development of new scalable methods for obtaining epoxyphosphazene-containing epoxy resins based on available starting materials with reduced viscosity and improved technological properties is of great scientific and practical interest and may contribute to accelerating the widespread use of phosphazene-containing resins as components of high-tech flame-retardant polymer composite materials.

In order to exclude phenolate synthesis in the known method [53] (Figure 2) and to obtain pre-formulated PEOs with lower viscosity and greater phosphorus content in the present work, by analogy with $[55,56]$, PEO was synthesized by direct interaction of HCP, phenol, bisphenol A, and epichlorohydrin. 


\section{Materials and Methods}

In the present work PEO was synthesized by direct interaction of $\mathrm{HCP}$, phenol and bisphenol A (BPA) in epichlorohydrin (ECH) medium as reagent and solvent in the presence of $\mathrm{KOH}$ with a role of both $\mathrm{HCl}$ acceptor and epoxy-forming reagent (Figure 3, Method A).

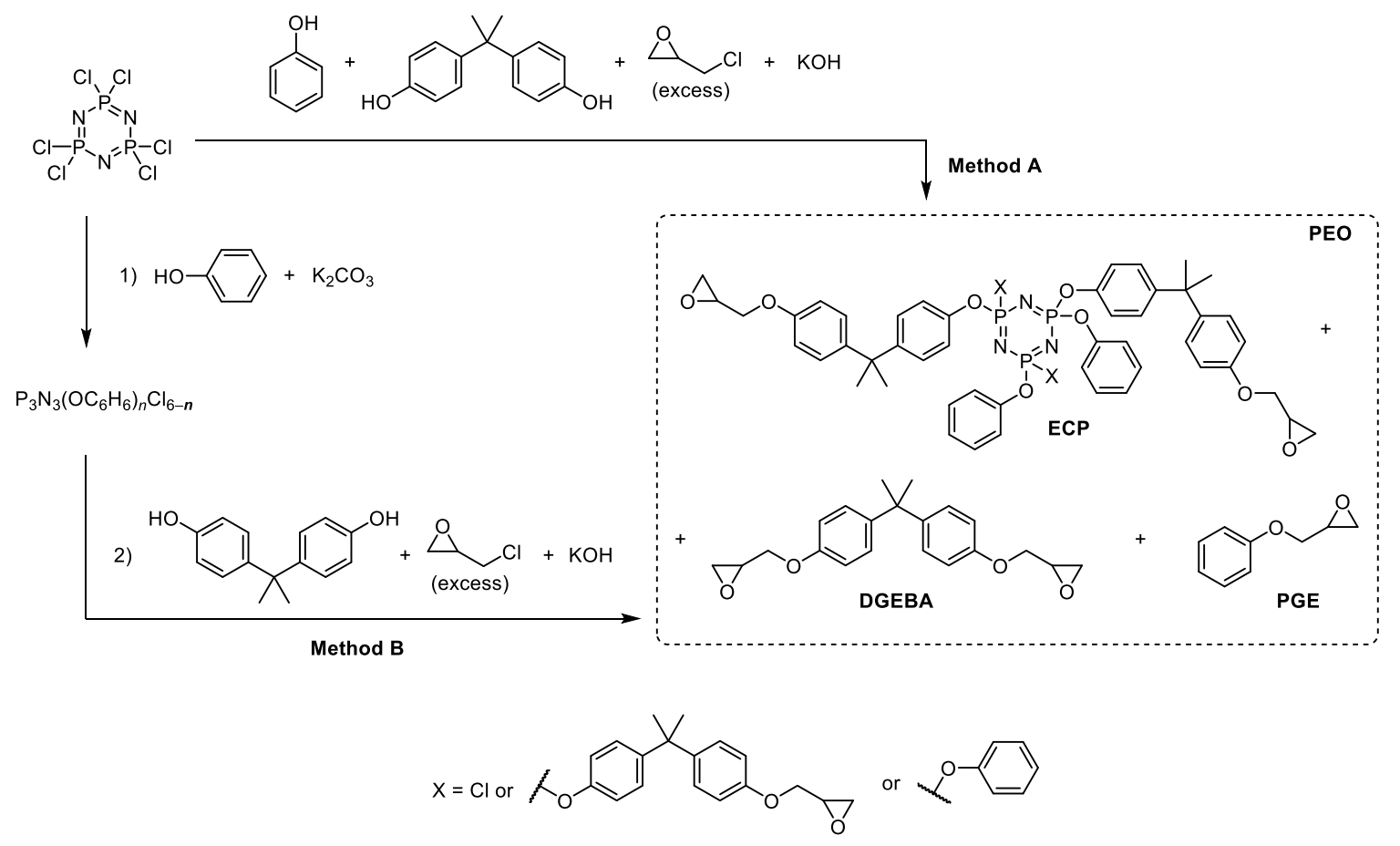

Figure 3. Single-stage synthesis of phosphazene-containing epoxy oligomers by direct interaction of hexachlorocyclotriphosphazene (HCP), phenol and bisphenol A in epichlorohydrin medium (this work).

For comparison, stepwise replacement of chlorine atoms in HCP was carried out first on phenoxy groups, and then on the residues of bisphenol $\mathrm{A}$ in the presence of potassium carbonate as $\mathrm{HCl}$ acceptor on the first stage and with $\mathrm{KOH}$ on the second (Figure 3, Method B).

\subsection{Starting Materials}

Hexachlorocyclophosphazene-a white crystalline substance with m.p. of $113^{\circ} \mathrm{C}$; nuclear magnetic resonance (NMR) ${ }^{31} \mathrm{P}$-singlet spectrum with $\delta_{\mathrm{P}}=19.9 \mathrm{ppm}$, was obtained by the method [58]. Potassium hydroxide in the form of $90.0 \%$ pure white pellets (JSC KAUSTIK, Volgograd, Russia) was used without purification, the content of crystallization water determined by acid-base titration was about $10 \%$. Epichlorohydrin (Solvay, Tavaux, France) with the content of the main substance of $99.8 \%$ was distilled before use as a colorless liquid, b.p. $118^{\circ} \mathrm{C}$. Potassium carbonate (Sigma-Aldrich, St. Louis, MI, USA) was dried in vacuum at $100^{\circ} \mathrm{C}$ before use as a white crystalline substance in the form of powder, soluble in water. Bisphenol A (PJSC Kazanorgsintez, Kazan, Russia) was purified via repeated recrystallization from chlorobenzene to yield a product with m.p. of $156.5^{\circ} \mathrm{C}$. Phenol (Sigma-Aldrich, St. Louis, MI, USA) was distilled before use into white crystals, m.p. $40.0^{\circ} \mathrm{C}$. Solvents were purified according to known methods, their physical characteristics corresponded to the literature data [59].

\subsection{Synthesis of Epoxyphosphazenes}

\subsubsection{Single-Stage Synthesis of Phosphazene-Containing Epoxy Oligomers (Method A)}

A $100 \mathrm{~mL}$ three-necked flask, equipped with a reflux condenser, a mechanical stirrer, and a thermometer, was charged with $1 \mathrm{~g}(0.0028 \mathrm{~mol})$ of $\mathrm{HCP}, 2.68 \mathrm{~g}(0.0144 \mathrm{~mol})$ of bisphenol A, $0.54 \mathrm{~g}$ 
$(0.0058 \mathrm{~mol})$ of phenol, and $65 \mathrm{~mL}$ of epichlorohydrin. The reaction mixture was heated to $50-55^{\circ} \mathrm{C}$ and thermostated at this temperature for $30 \mathrm{~min}$ until all solids were completely dissolved. After that, $2.32 \mathrm{~g}(0.0414 \mathrm{~mol})$ of potassium hydroxide was added and the process was conducted for $2 \mathrm{~h}$ at a temperature of $60^{\circ} \mathrm{C}$. At the end of the synthesis, the hot solution was filtered off and excess solvent was distilled off. The resulting mixture of epoxy oligomers was dried in vacuo at $85^{\circ} \mathrm{C}$. The reaction product is a slightly colored viscous liquid. The yield was $3.96 \mathrm{~g} \mathrm{(71 \% ).}$

\subsubsection{Stepwise Synthesis of Phosphazene-Containing Epoxy Oligomers (Method B)}

A $100 \mathrm{~mL}$ three-necked flask, equipped with a reflux condenser, a mechanical stirrer, and a thermometer, was charged with $1 \mathrm{~g}(0.0028 \mathrm{~mol})$ of HCP, $0.54 \mathrm{~g}(0.0058 \mathrm{~mol})$ of phenol, $0.95 \mathrm{~g}$ $(0.0069 \mathrm{~mol})$ potassium carbonate, and $65 \mathrm{~mL}$ of epichlorohydrin. The reaction mixture was heated to $60{ }^{\circ} \mathrm{C}$ and the process was conducted for $2 \mathrm{~h}$ at this temperature. The reaction mixture was then cooled to $50{ }^{\circ} \mathrm{C}, 3.28 \mathrm{~g}(0.0144 \mathrm{~mol})$ of bisphenol A was charged and incubated at this temperature for $15 \mathrm{~min}$ until the bisphenol A was completely dissolved. After that, $2.32 \mathrm{~g}(0.0414 \mathrm{~mol})$ of potassium hydroxide was added and the process was conducted for $3 \mathrm{~h}$ at a temperature of $60{ }^{\circ} \mathrm{C}$. At the end of the synthesis, the hot solution was filtered off and excess solvent was distilled off. The resulting mixture of epoxy oligomers was dried in vacuo at $85^{\circ} \mathrm{C}$. The reaction product was a slightly colored viscous liquid. The yield was $4.18 \mathrm{~g}(75 \%)$.

\subsection{Methods of Analysis}

The ${ }^{31} \mathrm{P}$ and ${ }^{1} \mathrm{H}$ NMR spectra were measured in chloroform-d solutions with a Bruker AV-400 spectrometer (Bruker Corporation, Bremen, Germany) operating at 162 and $400 \mathrm{MHz}$, respectively. The signals due to the deuterated solvents were used as internal references. The chemical shifts of the signals were calculated relative to the signals of tetramethylsilane $\left({ }^{1} \mathrm{H}\right)$ and phosphoric acid $\left({ }^{31} \mathrm{P}\right)$, which were used as references. The spectra were processed with the help of the MestReNova Lab software package (Version 12.0.4, MESTRELAB RESEARCH, S.L, Santiago de Compostela, Spain).

MALDI-TOF mass spectrometric analysis was carried out on the Bruker Auto Flex II instrument (Bruker Corporation, Bremen, Germany).

The gas chromatography-mass-spectrometry (GC-MS) study was carried out on a VARIAN-3800 $\mathrm{CP} / 4000$ MS chromatograph-mass spectrometer (manufactured by Varian, Palo Alto, CA, USA). Separation of the substances was carried out using a VF-5ms chromatographic capillary column with a length of $30 \mathrm{~m}$, an internal diameter of $0.25 \mathrm{~mm}$, and a fixed-phase layer thickness of $0.25 \mu \mathrm{m}$. The carrier gas was helium. The injector temperature was $280^{\circ} \mathrm{C}$. The volume of the injected sample was $1 \mu \mathrm{L}$. The temperature of the column thermostat changed from $50{ }^{\circ} \mathrm{C}(1 \mathrm{~min})$ to $280{ }^{\circ} \mathrm{C}(10 \mathrm{~min})$ at a rate of $10{ }^{\circ} \mathrm{C} / \mathrm{min}$. The temperature of the ion source and the interface was 230 and $280{ }^{\circ} \mathrm{C}$. The mass spectra of the substances were registered in the electron impact regime in the mass range 33-1000 Da. The processing of the obtained data was carried out with the usage of computer software "Varian MS Workstation", the identification of the substances was carried out using the NIST 11 mass-spectra library.

The gel-permeation chromatography (GPC) was carried out on Shimadzu LC-20 Prominence (Kyoto, Japan) chromatograph equipped with refractometric and UV detector (a wavelength of $264 \mathrm{~nm}$,) and a PSS column (SDV; $300 \mathrm{~mm} \times 8 \mathrm{~mm} ; 1000 \mathrm{~A}$, separation within 100-60,000 Da), tetrahydrofuran (THF) was used as an eluent $(1 \mathrm{~mL} / \mathrm{min})$. Molecular mass values were estimated with the use of a polystyrene calibration curve. Elemental analysis was carried out by spectrophotometry.

In the present paper, epoxy group content (in wt \%) is the weight of oxirane groups $\left(-\mathrm{CHCH}_{2} \mathrm{O}\right)$ divided by the total molecular weight of epoxy resin. Thus, the theoretical content of epoxy groups was calculated by the formula:

$$
E_{\text {calc }}=\frac{43 \times n}{M} 100 \%
$$


where 43 and $M$ are the molecular weights of the oxirane group and the whole epoxy resin molecule, respectively, and $n$ is the number of oxirane groups in the epoxy resin molecule. The experimental epoxy group content was determined by the method of reverse acid-base titration [60-62]. In these methods, glycidyl groups are converted to chlorohydrin groups by dissolving the sample of epoxy resin in hydrochloric acid acetone solution followed by titration of the excess of hydrochloric acid with $\mathrm{NaOH}$ solution. The experimental epoxy group content is calculated by the formula:

$$
E_{\exp }=\frac{\left(V-V_{0}\right) \times 43 \times N}{g \times 1000} 100 \%
$$

where $V$ is the amount of $\mathrm{NaOH}$ solution for titration of a sample containing epoxy resin in $\mathrm{mL}$; $V_{0}$ is the amount of $\mathrm{NaOH}$ solution for titration of blank sample without epoxy resin in $\mathrm{mL} ; 43$ is the molecular weight of the oxirane group; $N$ is the concentration of $\mathrm{NaOH}$ solution, $\mathrm{mol} \cdot \mathrm{L}^{-1}$; and $g$ is the mass of epoxy resin sample in $\mathrm{g}$.

The viscosity of epoxy oligomers was evaluated on a Reotest- 2 rotational viscometer with a working cone-plane unit. The viscosity of the PEOs obtained in present and earlier papers was compared with conventional low molecular weight bisphenol A based epoxy resin D.E.R. ${ }^{\mathrm{TM}} 332$ epoxy resin (Dow Chemical, Midland, TX, USA) with the epoxy group content of $24.6 \%-25.1 \%$ and epoxy equivalent of 171-175 which is referenced as DGEBA and with ERISYS®Resorcinol diglycidyl ether RDGE (CVC Thermoset Specialties, Moorestown, NJ, USA) with the epoxy group content of $34.4 \%-36.4 \%$ and epoxy equivalent of $118-125$.

\section{Results and Discussion}

The composition and structure of the phosphazene component of the resulting mixture of epoxides were evaluated by combination of ${ }^{31} \mathrm{P}$ NMR spectroscopy and MALDI-TOF spectrometry (Figures 4 and 5) and the organic component by gas chromatography-mass spectrometry.

According to ${ }^{31} \mathrm{P}$ NMR spectroscopy, irrespective of the initial mole ratio of HCP:phenol:bisphenol A compounds with pentasubstituted triphosphazene rings predominate in the phosphazene fraction $\left(\mathrm{AB}_{2}\right.$ system with triplet $\delta_{\mathrm{p}}=20-26 \mathrm{ppm}$ and doublet $\left.\delta_{\mathrm{p}}=8-10 \mathrm{ppm}\right)$ together with insignificant amounts of tetraaryloxy-substituted compounds $\left(\mathrm{AB}_{2}\right.$ system with doublet at $\delta_{\mathrm{p}}=20-22 \mathrm{ppm}$ and triplet at $\delta_{\mathrm{p}}=5-8 \mathrm{ppm}$ ).

Laser mass spectrometry data confirm the presence in the phosphazene fraction of mainly pentaaryloxy-substituted HCP, containing residues of phenol and diphenol in various proportions in the substituents near phosphorus atom (Figure 4, Table 1).

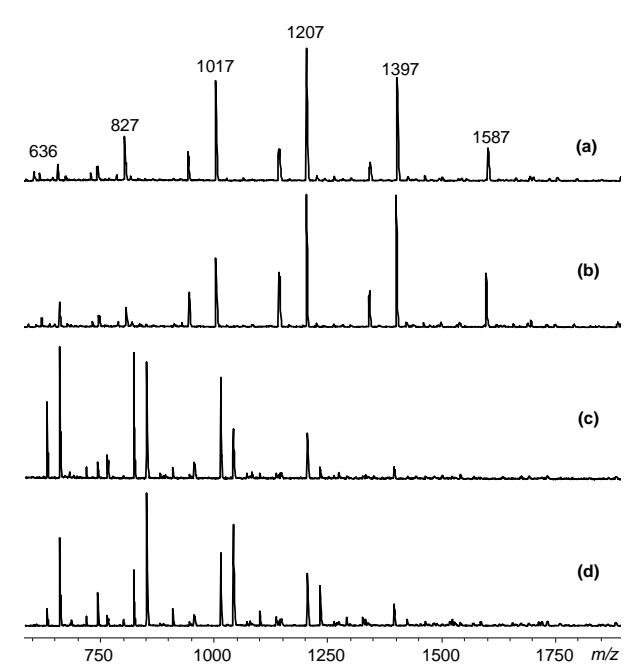

Figure 4. MALDI-TOF mass spectra of epoxycyclophosphazenes synthesized according to scheme A at molar ratios of HCP:phenol:bisphenol $\mathrm{A}=1: 2: 5$ (a), 1:2:6 (b), 1:4:3 (c), and 1:4:4 (d). 
The content of compounds with different ratios of mono- and diphenolic aryloxy radicals as substituents near phosphorus atom can be controlled by varying the initial ratio of HCP:phenol:bisphenol A, as follows from Figure 4.

The quantitative composition of PEOs was determined from the relative intensity of the peaks on the MALDI-TOF spectra. On the example of the initial molar ratio of HCP:phenol:bisphenol A equal to 1:3:5 the content of individual compounds in the phosphazene fractions formed by methods A and B (Figure 3) is compared in Table 1.

More homogeneous is the composition of PEOs obtained according to method A (Figure 3): It contains four basic compounds with one, two, three, and four epoxy groups (Figure 5a and Table 1).

It is noteworthy that there are no compounds with four and five epoxy groups in the B synthesis product, but they appear in an amount up to $10 \mathrm{wt} \%$ of aryloxyphosphazenes with unsubstituted $\mathrm{OH}$ groups of bisphenol A radicals (peaks with $m / z=960$ and 1150 in Figure 5b).

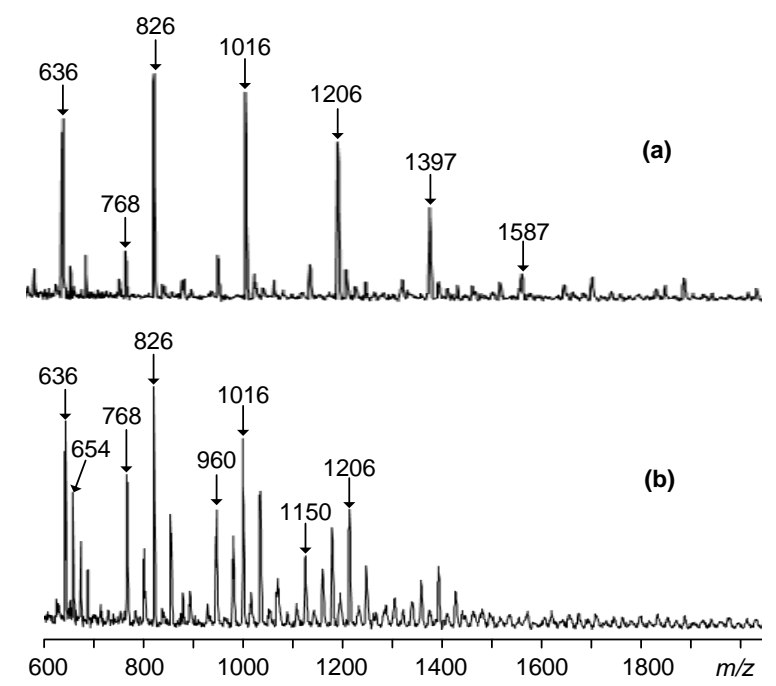

Figure 5. MALDI-TOF mass spectra of epoxycyclophosphazenes synthesized according to schemes A (a) and B (b) at molar ratios of HCP: phenol: bisphenol A = 1:3:5.

Table 1. The content of the phosphazene fractions of products synthesized by schemes A and B according to the data of MALDI-TOF-spectrometry. The molar ratio of HCP: phenol: bisphenol A=1:3:5.

\begin{tabular}{|c|c|c|c|}
\hline \multirow[t]{2}{*}{$m / z$} & \multirow[t]{2}{*}{ Compound Formula ${ }^{1}$} & \multicolumn{2}{|c|}{$\begin{array}{l}\text { Relative Content of the Compound (\% } \\
\text { weight) in the Product, Obtained via }\end{array}$} \\
\hline & & Method A & Method B \\
\hline 636 & $\mathrm{P}_{3} \mathrm{~N}_{3} \mathrm{Cl}(\mathrm{OPh})_{5}$ & 12.3 & 3.6 \\
\hline 654 & $\mathrm{P}_{3} \mathrm{~N}_{3} \mathrm{Cl}_{4}(\mathrm{OPh})$ (OArOGly) & - & 3.0 \\
\hline 768 & $\mathrm{P}_{3} \mathrm{~N}_{3} \mathrm{Cl}_{2}(\mathrm{OPh})_{3}$ (OArOGly) & 1.6 & 7.2 \\
\hline 826 & $\mathrm{P}_{3} \mathrm{~N}_{3} \mathrm{Cl}(\mathrm{OPh})_{4}(\mathrm{OArOGly})$ & 14.0 & 8.6 \\
\hline 958 & $\mathrm{P}_{3} \mathrm{~N}_{3} \mathrm{Cl}(\mathrm{OPh})_{3}(\mathrm{OArOGly})\left(\mathrm{OArOGly}^{\prime}\right)$ & - & 5.0 \\
\hline 960 & $\mathrm{P}_{3} \mathrm{~N}_{3} \mathrm{Cl}(\mathrm{OPh})_{3}(\mathrm{OArOH})(\mathrm{OArOGly})$ & - & 8.5 \\
\hline 1016 & $\mathrm{P}_{3} \mathrm{~N}_{3} \mathrm{Cl}(\mathrm{OPh})_{3}(\mathrm{OArOGly})_{2}$ & 22.2 & 9.2 \\
\hline 1150 & $\mathrm{P}_{3} \mathrm{~N}_{3} \mathrm{Cl}(\mathrm{OPh})_{2}(\mathrm{OArOH})(\mathrm{OArOGly})_{2}$ & - & 3.0 \\
\hline 1206 & $\mathrm{P}_{3} \mathrm{~N}_{3} \mathrm{Cl}(\mathrm{OPh})_{2}(\mathrm{OArOGly})_{3}$ & 25.0 & 19.3 \\
\hline 1397 & $\mathrm{P}_{3} \mathrm{~N}_{3} \mathrm{Cl}(\mathrm{OPh})(\mathrm{OArOGly})_{4}$ & 16.7 & - \\
\hline 1587 & $\mathrm{P}_{3} \mathrm{~N}_{3} \mathrm{Cl}(\mathrm{OArOGly})_{5}$ & 1.0 & - \\
\hline
\end{tabular}


Since the organic part of the synthesized epoxy-oligomers could not be evaluated well by MALDI-TOF, a gas chromatography-mass spectrometry method was used for its analysis (Figures 6 and 7). As follows from Figure 6, the organic epoxide includes several compounds with different retention times in a chromatographic column.

There is insufficient information in the literature about the analysis of epoxy monomers by gas chromatography-mass spectrometry. However, given the fact that in order to achieve a satisfactory separation and to ensure the release of substances from the column, it was necessary to increase the temperature of the latter up to $280^{\circ} \mathrm{C}$, it can be assumed that fragmentation of the product components could occur not only as a result of electron impact during ionization, but also as a result of thermal exposure in a column.

The molecular weights of starting compounds and their derivatives formed as a result thermal exposure and electron impact estimated from the mass spectra allowed us to propose their chemical formulas which are listed in Table 2.

As follows from the data of gas chromatography-mass spectrometry, the main compounds in the organic part of the epoxide synthesized according to both schemes are mono- and diglycidyl ethers of bisphenol A with a predominant content of the latter ( $\sim 70 \%$ and $\sim 20 \%$ for methods A and B, respectively).

Phenylglycidyl ether (PGE) is present in a small amount only in the product synthesized according to method B (5\%-10\%). This indicates the preferential interaction of phenol not with epichlorohydrin, but with HCP at the initial stages of the process.

The results of the analysis of the electron impact mass spectra of the fractions (Figure 6) isolated from the chromatographic column allow us to draw the following conclusions (Table 2). The reaction products eluted from the column as a result of electron impact upon registration of the mass spectra may undergo some transformations, and the main among them is the transformation of the isopropylidene group into ethylidene:

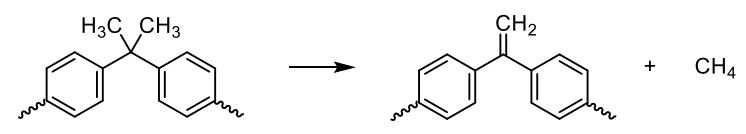

As a result, the majority of compounds fixed on mass spectra (peaks 3-8 in Figure 6) have a molecular weight of 16 units less than expected, which in our opinion is due to the elimination of $\mathrm{CH}_{4}$.

A similar decomposition of the isopropylidene group with the formation of a double bond was observed earlier under conditions of the synthesis bisphenol A based hydroxyaryloxycyclotriphosphazenes at $170{ }^{\circ} \mathrm{C}[60]$ :

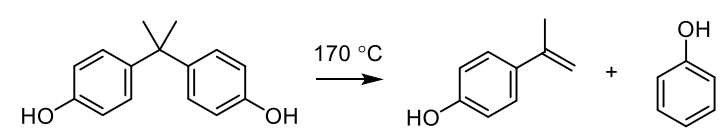

The main component of the organic fraction of the resulting epoxides is diglycidyl ether of bisphenol A (DGEBA), the highest yield ( 70\%) of which is achieved in the synthesis of method A with the simultaneous feeding of starting reagents.

The compounds' formulas given in the sixth column of Table 2 show the elimination of methane from the corresponding compounds of the formulas given in the third column of this table.

It is noteworthy that in the reaction mixture there is practically no monoglycidyl ether of bisphenol A (MGEBA) with a molecular weight of 284 , which corresponds to peaks with an insignificant intensity in the mass spectra of fraction 5 . The main compound in fraction 5 for both synthetic schemes is the compound with a molecular weight of 268-monoglycidyl ether of 4,4' -dihydroxydiphenol-1,1-ethenyl.

As for compounds with one chlorohydrin group and the central ethenyl group (peak 8 on the chromatogram), the lack of a tendency to their dehydrochlorination is apparent due to both the heterogeneity of the process ( $\mathrm{KOH}$ is insoluble in the reaction medium) and its insignificant duration $(2 \mathrm{~h})$.

From Figures 6 and 7, it follows that the organic epoxide formed according to Method A (Figure 3) together with epoxycyclophosphazene is more pure-it contains about $90 \%$ mono- and diglycidyl ethers with minimal amounts of initial phenol and bisphenol A. 
The properties of different PEO obtained in this work and other PEOs [55-57] that can be synthesized using the one-pot method are summarized at Table 3. GPC was used (Figure 8) to determine the relative content of phosphazene and organic fractions (Figure 8a, Table 3). For comparison, the fractional composition of epoxyphosphazenes based on resorcinol obtained in a previous study [57] was also determined (Figure 8 b, Table 3).

(a)

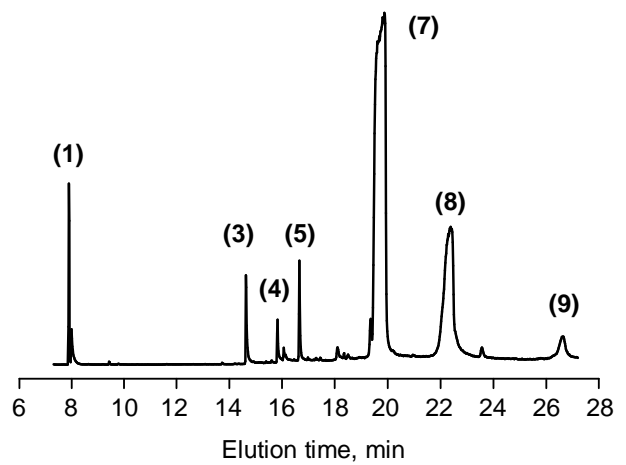

(b)

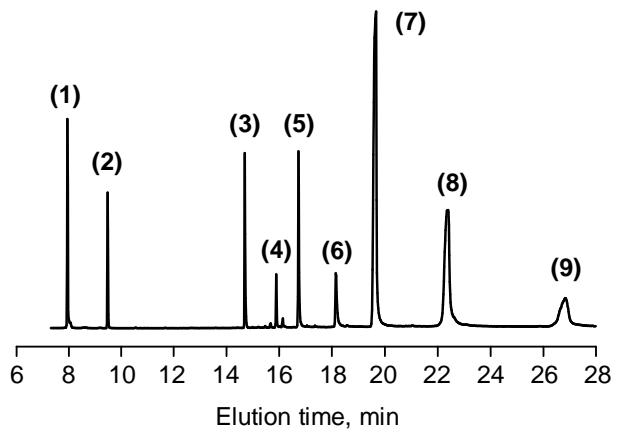

Figure 6. Chromatograms of organic epoxides obtained by schemes A (a) and B (b).

(1)

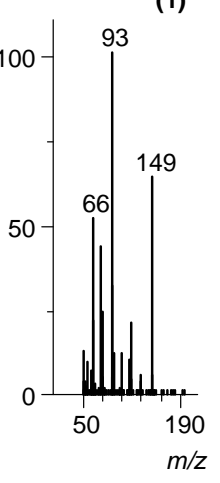

(6)

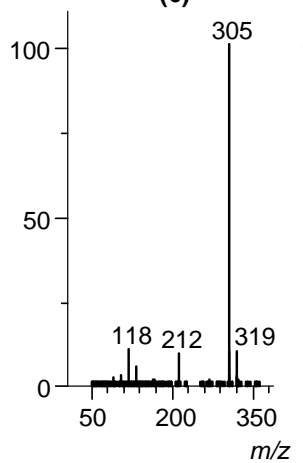

(2)

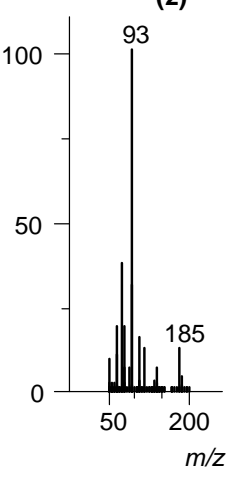

(3)
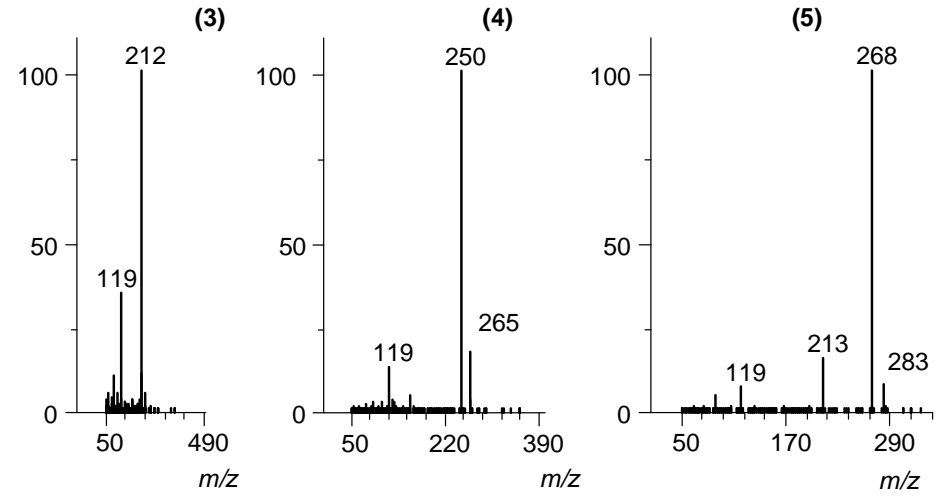

(7)
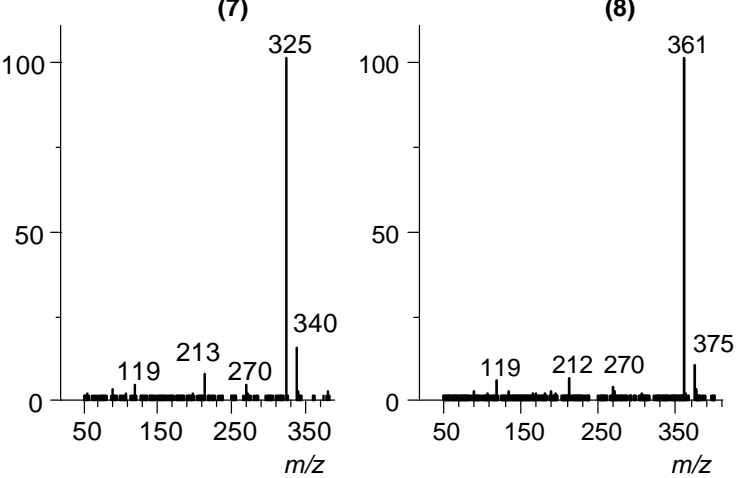

(8)

(9)

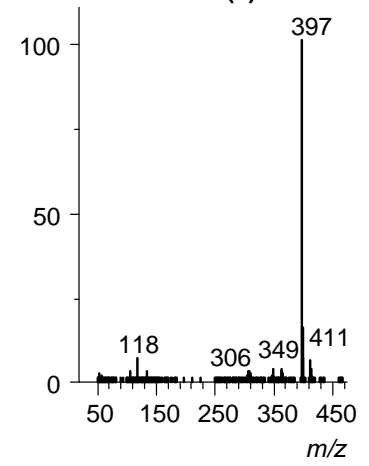

Figure 7. Mass spectra of fractions of organic epoxides synthesized according to methods A (Figure 3) and B (Figure 4). Spectrum numbers (1-9) correspond to the numbers of fractions on chromatograms, Figure 6. 
Table 2. Results of chromatography-mass spectrometric analysis of organic fractions of reaction products obtained according to schemes A and B. Molar ratio of HCP:phenol:bisphenol A = 1:3:5.

\begin{tabular}{|c|c|c|c|c|c|c|c|c|}
\hline \multicolumn{5}{|c|}{ Chromatography Data (Figure 6) } & \multicolumn{4}{|c|}{ Mass-Spectrometric Data (Figure 7) } \\
\hline \multirow[t]{2}{*}{ Peak No } & \multirow{2}{*}{$\begin{array}{l}\text { Elution Time } \\
\quad(\min )\end{array}$} & \multirow{2}{*}{$\begin{array}{l}\text { Probable Formula }{ }^{1} \text { of } \\
\text { the Compound at the } \\
\text { Output of the Column }\end{array}$} & \multirow{2}{*}{$\begin{array}{c}\text { Calculated } \\
\text { Molecular Weight }\end{array}$} & \multirow{2}{*}{$\begin{array}{l}\text { Content }{ }^{2} \text { of the } \\
\text { Compound (wt } \%)\end{array}$} & \multirow{2}{*}{$\begin{array}{l}\text { The Most Likely } \\
\text { Formula }\end{array}$} & \multirow{2}{*}{$\begin{array}{c}\text { Calculated } \\
\text { Molecular Weight }\end{array}$} & \multicolumn{2}{|c|}{$\begin{array}{l}\text { Observed } m / z \text { Values of the } \\
\text { Products Obtained by Method }\end{array}$} \\
\hline & & & & & & & $\mathbf{A}$ & B \\
\hline \multirow[t]{2}{*}{1} & 7.8 & $\mathrm{PhOH}$ & 93 & $2.0 / 7.6$ & $\mathrm{PhOH}$ & 93 & 93 & 93 \\
\hline & 7.9 & $\mathrm{PhOCH}_{2} \mathrm{CH}=\mathrm{CH}_{2}$ & 134 & $0.5 /-$ & $\mathrm{PhOCH}_{2} \mathrm{CH}=\mathrm{CH}_{2}$ & 134 & 133 & none \\
\hline 2 & 9.3 & PhOGly & 150 & $0.9 / 4.8$ & PhOGly & 150 & none & 149 \\
\hline 3 & 14.6 & $\mathrm{HOArOH}$ & 228 & $1.0 / 6.3$ & $\mathrm{HOAr}{ }^{\prime} \mathrm{OH}$ & 212 & 212 & 212 \\
\hline 4 & 15.8 & HOArOGly & 284 & $0.8 / 1.9$ & $\mathrm{HOAr}^{\prime} \mathrm{OCH}_{2} \mathrm{CH}=\mathrm{CH}_{2}$ & 252 & 250 & 250 \\
\hline 5 & 16.7 & HOArOGly & 284 & $2.0 / 8.2$ & HOAr'OGly & 268 & $268+283$ & $268+283$ \\
\hline 6 & 18.7 & HOAr'OGly' & 306.5 & $-/ 4.1$ & HOAr'OGly' & 306.5 & none & 305 \\
\hline 7 & 19.8 & GlyOArOGly & 340 & $66.8 / 45.9$ & GlyOArOGly & 325 & $325+340$ & $325+340$ \\
\hline 8 & 22.4 & Gly'OAr'OGly & 361 & $21.2 / 2 ., 1$ & Gly'OAr'OGly & 361 & 361 & 361 \\
\hline 9 & 26.8 & 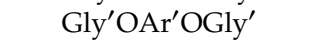 & 397 & $4.6 /-$ & 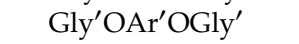 & 397 & 397 & none \\
\hline
\end{tabular}


(a)

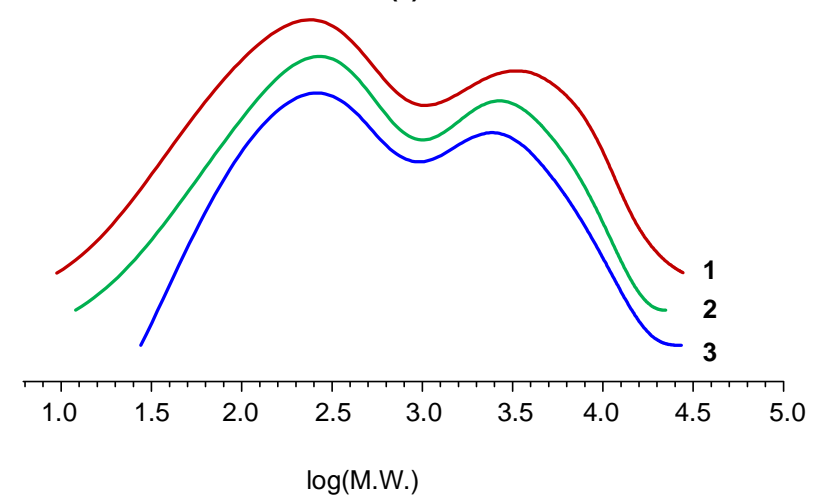

(b)

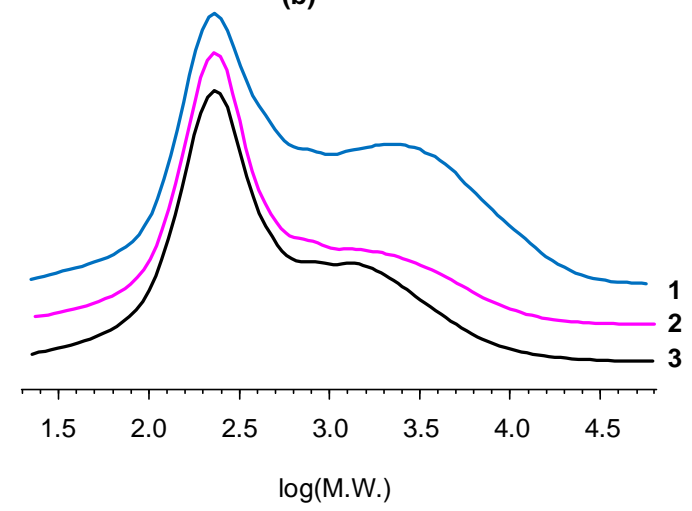

Figure 8. Gel-permeation chromatograms of PEO obtained in this by scheme A (a) with molar ratio of HCP:phenol:bisphenol A = 1:2:6 (1), 1:4:4 (2), 1:3:5 (3); and of resorcinol-based PEO (b) obtained in previous work [57] by interaction of HCP with resorcinol with molar ratio of HCP:resorcinol = 1:12 (1), 1:16 (2) and 1:24 (normalized to the height of the main peak).

The phosphazene component contents found from GPC data and calculated from the phosphorus content value are close to each other and are about $50 \%-60 \%$ for phenol-bisphenol A based product and are up to $45 \%$ for resorcinol-based product. The values of the weight average molecular weight according to GPC exceed the values obtained by the MALDI-TOF method, which can indicate both the limited applicability of the standard polystyrene calibration for these systems and the fact that high molecular weight particles may not be fixed by the MALDI-TOF method due to their limited volatility. However, the tendency of an increase in the average molecular weight with an increase in the content of the phosphazene component is confirmed by both GPC and MALDI-TOF, regardless of the nature of the starting reagents. It should be noted that the molecular weight values of the low molecular weight organic fraction determined by GPC and GC-MS are close and correspond to the theoretical assumption that its main component is diphenol diglydyl ether. From elemental analysis and GPC data it follows that with a comparable content of undesirable chlorine, the PEO obtained in this work is characterized by the both highest content of phosphorus (up to $5.4 \%$ ) and phosphazene component (up to $61 \%$ ).

The usage of phenol as additional reagent lead to reduced average fuctionality of the product of 1.9-2.2, which is closer to commercial DGEBA or RDGE resins when compared to 2.2-2.5 for the mixtures based on only bisphenol A or resorcinol. When compared to resorcinol-based phosphazene-containing epoxy oligomers, the values of viscosity of PEO obtained in this work are slightly higher. However, the viscosity of PEO obtained in this work at a ratio of $\mathrm{HCP}$ :phenol:bisphenol $\mathrm{A}=1: 4: 4$ and industrial bisphenol A based epoxy resin (such as diglycidyl ether of bisphenol A, DGEBA) are comparable (Table 3). At the same time, the viscosity of PEOs obtained at any ratio of HCP:phenol:bisphenol A is significantly lower than that of bisphenol A based phosphazene-containing epoxy resins. Thus, it can be expected that the processing properties of the PEO synthesized in this work will be as close as possible to ordinary bisphenol A based epoxy resins. As was shown in [53], such PEO are cured by conventional curing agents to form compositions with reduced flammability, increased glass transition temperature, flexural strength, and modulus while other characteristics of these compositions are at the level of commercially available epoxy materials. 
Table 3. The properties of phosphazene-containing epoxy oligomers ${ }^{1}$.

\begin{tabular}{|c|c|c|c|c|c|c|c|c|c|c|c|}
\hline \multirow{2}{*}{$\begin{array}{c}\text { Raw Reagents } \\
\text { Ratio }\end{array}$} & \multirow{2}{*}{$\begin{array}{c}\text { Mixture } \\
\text { Average } \\
\text { Functionality }\end{array}$} & \multicolumn{4}{|c|}{ Content (wt\%) } & \multicolumn{3}{|c|}{ Average Molecular Weight } & \multicolumn{3}{|c|}{ Viscosity (Pa-s) at the Temperature of $\left({ }^{\circ} \mathrm{C}\right)$} \\
\hline & & $\begin{array}{l}\text { Epoxy } \\
\text { Group }\end{array}$ & $\mathbf{P}$ & $\mathrm{Cl}$ & $\begin{array}{c}\text { Phosphazene } \\
\text { Fraction }^{2}\end{array}$ & $\begin{array}{c}\text { Entire Mixture }^{3} \\
M_{\mathrm{w}} / M_{\mathrm{n}}\end{array}$ & $\begin{array}{l}\text { Organic } \\
\text { Fraction }\end{array}$ & $\begin{array}{l}\text { Phosphazene } \\
\text { Fraction }\end{array}$ & 20 & 40 & 70 \\
\hline \multicolumn{12}{|c|}{ DGEBA } \\
\hline- & 2.0 & $24.6-25.1$ & - & - & - & $\begin{array}{l}\text { 346/- } \\
\text { RDGE }\end{array}$ & - & - & 5.83 & 0.86 & 0.06 \\
\hline- & 2.0 & $34.4-36.4$ & - & - & - & 243/- & - & - & 1.10 & 0.11 & 0.03 \\
\hline HCP:BPA & \multicolumn{11}{|c|}{ PEOs obtained by interaction of HCP with BPA and ECH $[55,56,61]$} \\
\hline $1: 12$ & 2.3 & 20.0 & 1.8 & 1.5 & $36 / 30$ & $1212 / 681$ & $340^{5}$ & 1486 & - & 130 & 2 \\
\hline $1: 16$ & 2.2 & 21.4 & 1.5 & 1.3 & $30 / 25$ & $931 / 627$ & & 1492 & 440 & 78 & 2 \\
\hline HCP:Resorcinol & \multicolumn{11}{|c|}{ PEOs obtained by interaction of HCP with resorcinol and ECH [57] } \\
\hline $1: 12$ & 2.4 & 21.0 & 4.0 & 4.4 & $45 / 43$ & $2350 / 380$ & & 1054 & 8.33 & 6.15 & 0.36 \\
\hline $1: 16$ & 2.3 & 28.6 & 3.0 & 2.4 & $30 / 32$ & $1260 / 260$ & $220^{3}$ & 999 & 2.43 & 1.94 & 0.15 \\
\hline $1: 24$ & 2.2 & 29.6 & 2.0 & 1.9 & $23 / 21$ & $1130 / 260$ & & 957 & 1.71 & 0.45 & 0.05 \\
\hline HCP:PhOH:BPA & \multicolumn{11}{|c|}{ PEOs obtained by interaction of $\mathrm{HCP}$ with BPA, phenol and $\mathrm{ECH}^{7}$ (this work) } \\
\hline 1:2:6 & 2.2 & 16.1 & 4.6 & 2.2 & $61 / 54$ & $4246 / 288$ & & 1211 & 64.6 & 13.7 & 0.8 \\
\hline 1:3:5 & 2.0 & 15.5 & 5.0 & 2.3 & $61 / 51$ & $3459 / 413$ & $340^{5}$ & 1058 & 58.6 & 10.6 & 0.8 \\
\hline
\end{tabular}

${ }^{4}$ My 


\section{Conclusions}

The phosphazene-containing epoxy oligomers obtained in the present work have an epoxy group content within $15-16 \mathrm{wt} \%$, phosphorus content within $4.6 \%-5.4 \%$ and epoxyphosphazene component content of $50 \%-60 \%$. These phosphazene-containing epoxy oligomers may be cured by conventional curing agents to form materials with reduced flammability, while other characteristics of these compositions are at the level of commercially available epoxy materials [53]. The viscosity of obtained epoxyphosphazene-containing resins is comparable to conventional bisphenol A based epoxies, and is much lower in comparison to similar epoxyphosphazene resins based on bisphenol A. Thus, the obtained epoxyphosphazene resins may be used as a component of a binder for composite materials, adhesives, and paints.

Author Contributions: Conceptualization, V.V.K. and I.S.S.; experiment design, synthesis and data analysis, Y.V.B., I.S.S. and A.V.E.; GC-MS analysis, D.A.K.; MALDI-TOF analysis, R.S.B.; resources and materials, J.M. and Y.V.B.; writing-original draft preparation, I.S.S.; writing-review and editing, V.V.K. and S.N.F.

Funding: The research is supported by the Ministry of Science and Higher Education and of The Russian Federation within the framework of state contract NO. 14.574.21.0171 (unique identifier RFMEFI57417X0171).

Acknowledgments: We thank K.A. Brigadnov for technical assistance and participation in the discussions; A.S. Tupikov and I.A. Sarychev for GPC analysis of PEO.

Conflicts of Interest: The authors declare no conflict of interest.

\section{References}

1. Biron, M. Thermosets and Composites: Material Selection, Applications, Manufacturing and Cost Analysis; Elsevier: Amsterdam, The Netherlands, 2013; ISBN 978-1-4557-3125-1.

2. Dodiuk, H.; Goodman, S.H. Handbook of Thermoset Plastics; William Andrew: San Diego, CA, USA, 2013; ISBN 978-1-4557-3109-1.

3. Petrie, E.M. Epoxy Adhesive Formulations; McGraw Hill Professional: New York, NY, USA, 2005; ISBN 978-0-07-158908-6.

4. Flick, E.W. Epoxy Resins, Curing Agents, Compounds, and Modifiers: An Industrial Guide; William Andrew: San Diego, CA, USA, 2012; ISBN 978-0-8155-1708-5.

5. Visakh, P.M.; Arao, Y. (Eds.) Flame Retardants: Polymer Blends, Composites and Nanocomposites, 1st ed.; Engineering Materials; Springer International Publishing: Cham, Switzerland, 2015; ISBN 978-3-319-03466-9.

6. Lu, S.; Hamerton, I. Recent developments in the chemistry of halogen-free flame retardant polymers. Prog. Polym. Sci. 2002, 27, 1661-1712. [CrossRef]

7. Rodriguez, F.; Cohen, C.; Ober, C.K.; Archer, L. Principles of Polymer Systems, Sixth Edition; CRC Press: Boca Raton, FL, USA, 2014; ISBN 978-1-4822-2378-1.

8. Amirova, L.M. Fosforsoderzhashhie i Metallkoordinirovannye Jepoksidnye Polimernye Materialy [Фосфорсодержащие и металлкоординированные эпоксидные полимерные материалы]. Ph.D. Thesis, Kazan National Research Technological University, Kazan, Russia, 2004.

9. Amirova, L.M.; Andrianova, K.A. Gradient polymeric materials based on poorly compatible epoxy oligomers. J. Appl. Polym. Sci. 2006, 102, 96-103. [CrossRef]

10. Amirova, L.M.; Stroganov, V.F.; Sakhabieva, E.V. Optical Materials the Based on Low Flammable Epoxy Resins. Int. J. Polym. Mater. Polym. Biomater. 2000, 47, 43-60. [CrossRef]

11. Horrocks, A.R.; Price, D. Advances in Fire Retardant Materials; Elsevier: Amsterdam, The Netherlands, 2008; ISBN 978-1-84569-507-1.

12. Salmeia, K.A.; Gaan, S. An overview of some recent advances in DOPO-derivatives: Chemistry and flame retardant applications. Polym. Degrad. Stab. 2015, 113, 119-134. [CrossRef]

13. Allcock, H. Phosphorus-Nitrogen Compounds: Cyclic, Linear, and High Polymeric Systems; Elsevier: Amsterdam, The Netherlands, 1972; ISBN 978-0-12-050560-9.

14. Levchik, S.V.; Weil, E.D. A Review of Recent Progress in Phosphorus-based Flame Retardants. J. Fire Sci. 2006, 24, 345-364. [CrossRef]

15. Allen, C.W. The Use of Phosphazenes as Fire Resistant Materials. J. Fire Sci. 1993, 11, 320-328. [CrossRef] 
16. Leu, T.-S.; Wang, C.-S. Synergistic effect of a phosphorus-nitrogen flame retardant on engineering plastics. J. Appl. Polym. Sci. 2004, 92, 410-417. [CrossRef]

17. Phosphazene|Chemical Products|Otsuka Chemical Co., Ltd. Available online: https://www.otsukac.co.jp/en/ products/flame-retardant/phosphazene/ (accessed on 23 December 2018).

18. Fantin, G.; Medici, A.; Fogagnolo, M.; Pedrini, P.; Gleria, M.; Bertani, R.; Facchin, G. Functionalization of poly(organophosphazenes)-III. Synthesis of phosphazene materials containing carbon-carbon double bonds and epoxide groups. Eur. Polym. J. 2012, 29, 1571-1579. [CrossRef]

19. Allcock, H.R.; Nelson, C.J.; Coggio, W.D. Photoinitiated graft poly(organophosphazenes): Functionalized immobilization substrates for the binding of amines, proteins, and metals. Chem. Mater. 1994, 6, 516-524. [CrossRef]

20. Chen-Yang, Y.W.; Lee, H.F.; Yuan, C.Y. A flame-retardant phosphate and cyclotriphosphazene-containing epoxy resin: Synthesis and properties. J. Polym. Sci. Part A Polym. Chem. 2000, 38, 972-981. [CrossRef]

21. Bertani, R.; Boscolo-Boscoletto, A.; Dintcheva, N.; Ghedini, E.; Gleria, M.; La Mantia, F.; Pace, G.; Pannocchia, P.; Sassi, A.; Scaffaro, R.; et al. New phosphazene-based chain extenders containing allyl and epoxide groups. Des. Monomers Polym. 2003, 6, 245-266. [CrossRef]

22. Scaffaro, R.; Botta, L.; La Mantia, F.P.; Magagnini, P.; Acierno, D.; Gleria, M.; Bertani, R. Effect of adding new phosphazene compounds to poly(butylene terephthalate)/polyamide blends. I: Preliminary study in a batch mixer. Polym. Degrad. Stab. 2005, 90, 234-243. [CrossRef]

23. El Gouri, M.; El Bachiri, A.; Hegazi, S.E.; Rafik, M.; El Harfi, A. Thermal degradation of a reactive flame retardant based on cyclotriphosphazene and its blend with DGEBA epoxy resin. Polym. Degrad. Stab. 2009, 94, 2101-2106. [CrossRef]

24. Liu, R.; Wang, X. Synthesis, characterization, thermal properties and flame retardancy of a novel nonflammable phosphazene-based epoxy resin. Polym. Degrad. Stab. 2009, 94, 617-624. [CrossRef]

25. El Gouri, M.; Cherkaoui, O.; Ziraoui, R.; El Harfi, A. Physico-chemical study of DGEBA epoxy resin flame retarded with an ecological flame retardant based on cyclotriphosphazene. J. Mater. Environ. Sci. 2010, 3, 157-162.

26. El Gouri, M.; El Bachiri, A.; Hegazi, S.E.; Rafik, M.; El Harfi, A. Fireproofing amelioration of epoxy resin material by way a reactive flame retardant based on cyclophosphazene. Phys. Chem. News 2010, 56, 128-137.

27. El Gouri, M.; Hegazi, S.E.; Rafik, M.; El Harfi, A. Synthesis and thermal degradation of phosphazene containing the epoxy group. Ann. Chim. Sci. Mater. 2010, 35, 27-39. [CrossRef]

28. Liu, F.; Wei, H.; Huang, X.; Zhang, J.; Zhou, Y.; Tang, X. Preparation and Properties of Novel Inherent Flame-Retardant Cyclotriphosphazene-Containing Epoxy Resins. J. Macromol. Sci. Part B 2010, 49, 1002-1011. [CrossRef]

29. El Gouri, M.; El Bachiri, A.; Hegazi, S.E.; Ziraoui, R.; Rafik, M.; El Harfi, A. A phosphazene compound multipurpose application-Composite material precursor and reactive flame retardant for epoxy resin materials. J. Mater. Environ. Sci. 2011, 2, 319-334.

30. Gu, X.; Huang, X.; Wei, H.; Tang, X. Synthesis of novel epoxy-group modified phosphazene-containing nanotube and its reinforcing effect in epoxy resin. Eur. Polym. J. 2011, 47, 903-910. [CrossRef]

31. Bai, Y.; Wang, X.; Wu, D. Novel cyclolinear cyclotriphosphazene-linked epoxy resin for halogen-free fire resistance: Synthesis, characterization, and flammability characteristics. Ind. and Eng. Chem. Res. 2012, 51, 15064-15074. [CrossRef]

32. El Gouri, M.; El Harfi, A. Chemical modification of hexachlorocyclotriphosphazene-Preparation of flame retardants and ecological flame retardant polymers. J. Mater. Environ. Sci. 2012, 3, 17-33.

33. Liu, J.; Tang, J.; Wang, X.; Wu, D. Synthesis, characterization and curing properties of a novel cyclolinear phosphazene-based epoxy resin for halogen-free flame retardancy and high performance. RSC Adv. 2012, 2, 5789-5799. [CrossRef]

34. Sun, J.; Wang, X.; Wu, D. Novel Spirocyclic Phosphazene-Based Epoxy Resin for Halogen-Free Fire Resistance: Synthesis, Curing Behaviors, and Flammability Characteristics. ACS Appl. Mater. Interfaces 2012, 4, 4047-4061. [CrossRef] [PubMed]

35. Feng, H.; Wang, X.; Wu, D. Fabrication of spirocyclic phosphazene epoxy-based nanocomposites with graphene via exfoliation of graphite platelets and thermal curing for enhancement of mechanical and conductive properties. Ind. Eng. Chem. Res. 2013, 52, 10160-10171. [CrossRef] 
36. Huang, X.; Wei, W.; Wei, H.; Li, Y.; Gu, X.; Tang, X. Preparation of heat-moisture resistant epoxy resin based on phosphazene. J. Appl. Polym. Sci. 2013, 130, 248-255. [CrossRef]

37. El Gouri, M.; El Mansouri, A.; El Gouri, R.; Hadik, N.; Cherkaoui, O.; Outzourhit, A.; El Harfi, A. Physical behaviour of epoxy resin material flame retarded with a reactive flame retardant based on cyclophosphazene. J. Mater. Environ. Sci. 2014, 5, 400-4007.

38. Lu, L.; Chen, Y.; Wang, S.; Yang, S.; Dong, X. Preparation and flame retardancy of MMT pattern synergy intumescent flame-retardant epoxy resin. Gaofenzi Cailiao Kexue Yu Gongcheng Polym. Mater. Sci. Eng. 2014, 30, 139-144.

39. Xu, G.R.; Xu, M.J.; Li, B. Synthesis and characterization of a novel epoxy resin based on cyclotriphosphazene and its thermal degradation and flammability performance. Polym. Degrad. Stab. 2014, 109, 240-248. [CrossRef]

40. Liu, H.; Wang, X.; Wu, D. Novel cyclotriphosphazene-based epoxy compound and its application in halogen-free epoxy thermosetting systems: Synthesis, curing behaviors, and flame retardancy. Polym. Degrad. Stab. 2014, 103, 96-112. [CrossRef]

41. Lakshmikandhan, T.; Sethuraman, K.; Chandramohan, A.; Alagar, M. Development of phosphazene imine-modified epoxy composites for low dielectric, antibacterial activity, and UV shielding applications. Polym. Compos. 2017, 38, E24-E33. [CrossRef]

42. Liu, H.; Wang, X.; Wu, D. Synthesis of a novel linear polyphosphazene-based epoxy resin and its application in halogen-free flame-resistant thermosetting systems. Polym. Degrad. Stab. 2005, 118, 45-58. [CrossRef]

43. Wu, Y.; Wang, X.; Jiang, L.; Mao, Y.; Zhao, D. Kinetics of thermal decomposition and flame retardance of phosphazene-containing epoxy resin. In Proceedings of the 10th Asia-Pacific Conference on Combustion, Beijing, China, 19-22 June 2015.

44. Takahashi, K.; Yamamoto, T.; Itoh, S.; Harakawa, K.; Kajiwara, M. Mechanical properties of epoxy resins cured by various amines. Zairyo J. Soc. Mater. Sci. Jpn. 1988, 37, 454-459. [CrossRef]

45. Yamamoto, T.; Takahashi, K.; Kon, Y.; Harakawa, K. Curing of epoxy resin with phosphazene derivatives. Kobunshi Ronbunshu 1988, 45, 851-856. [CrossRef]

46. Yamamoto, T.; Takahashi, K.; Kon, Y.; Kobayashi, K. Tensile Behavior and Heat Resistance of Epoxy Resin Cured with Phosphazene Derivatives. Kobunshi Ronbunshu 1989, 46, 177-181. [CrossRef]

47. Takahashi, K.; Ishikawa, N.; Komori, T.; Yoon, H.-S. Curing of an epoxy resin with $\mathrm{P}_{3} \mathrm{~N}_{3}\left(\mathrm{NH}_{2}\right)_{2}\left(\mathrm{OCH}_{2} \mathrm{CF}_{3}\right)_{4}$ and its mechanical properties. Kobunshi Ronbunshu 1990, 47, 727-734. [CrossRef]

48. Takahashi, K.; Ishikawa, N.; Yoon, H.-S. Mechanical properties of epoxy resins cured with $\mathrm{P}_{3} \mathrm{~N}_{3}\left(\mathrm{NH}_{2}\right)_{2}$ $\left(\mathrm{OC}_{6} \mathrm{H}_{4} \mathrm{Cl}\right)_{4}$. Kobunshi Ronbunshu 1990, 47, 757-762. [CrossRef]

49. Takahashi, K.; Ishikawa, N.; Yoon, H.-S. Resistance of epoxy resins cured with trichloro-tridimethylaminocyclotriphosphazene against chemical substances. Zairyo J. Soc. Mater. Sci. Jpn. 1990, 39, 1001-1006. [CrossRef]

50. Takahashi, K.; Ishikawa, N.; Kohno, T.; Yoon, H.-S. Water resistance of an epoxy resin cured with $\mathrm{P}_{3} \mathrm{~N}_{3} \mathrm{Cl}_{3}\left(\mathrm{~N}\left(\mathrm{CH}_{3}\right)_{2}\right)_{3}$ and the effect of glass flake reinforcement. Zairyo J. Soc. Mater. Sci. Jpn. 1991, 40, 458-463. [CrossRef]

51. Takahashi, K.; Nakashima, J.; Ishiguro, S. Mechanical properties of trifunctional epoxy resin with phosphazene derivatives. Kobunshi Ronbunshu 1994, 51, 717-723. [CrossRef]

52. Chen, Y.M.; Liao, Y.L.; Lin, J.J. Synergistic effect of silicate clay and phosphazene-oxyalkyleneamines on thermal stability of cured epoxies. J. Colloid Interface Sci. 2010, 343, 209-216. [CrossRef] [PubMed]

53. Terekhov, I.V.; Filatov, S.N.; Chistyakov, E.M.; Borisov, R.S.; Kireev, V.V. Synthesis of oligomeric epoxycyclotriphosphazenes and their properties as reactive flame-retardants for epoxy resins. Phosphorus Sulfur Silicon Relat. Elem. 2017, 192, 544-554. [CrossRef]

54. Kireev, V.V.; Bilichenko, Y.V.; Borisov, R.S.; Sirotin, I.S.; Filatov, S.N. Laser Mass Spectrometry Analysis of the Formation of Phosphazene-Containing Epoxy Oligomers. Polym. Sci. Ser. B 2018, 60, 243-262. [CrossRef]

55. Sirotin, I.S.; Bilichenko, Y.V.; Brigadnov, K.A.; Kireev, V.V.; Prudskov, B.M.; Borisov, R.S. Single-stage synthesis of phosphazene-containing epoxy oligomers. Polym. Sci. Ser. B 2014, 56, 471-476. [CrossRef]

56. Brigadnov, K.A.; Bilichenko, Y.V.; Polyakov, V.A.; Borisov, R.S.; Gusev, K.I.; Rudakova, T.A.; Filatov, S.N.; Kireev, V.V. Epoxy oligomers modified with epoxyphosphazenes. Polym. Sci. Ser. B 2016, 58, 549-555. [CrossRef] 
57. Sarychev, I.A.; Sirotin, I.S.; Borisov, R.S.; Mu, J.; Sokolskaya, I.B.; Bilichenko, J.V.; Filatov, S.N.; Kireev, V.V. Synthesis of Resorcinol-Based Phosphazene-Containing Epoxy Oligomers. Polymers 2019, 11, 614. [CrossRef]

58. Sirotin, I.S.; Bilichenko, Y.V.; Suraeva, O.V.; Solodukhin, A.N.; Kireev, V.V. Synthesis of oligomeric chlorophosphazenes in the presence of $\mathrm{ZnCl}_{2}$. Polym. Sci. Ser. B 2013, 55, 63-68. [CrossRef]

59. Riddick, J.A.; Bunger, W.B.; Sakano, T.K. Organic Solvents: Physical Properties and Methods of Purification; Wiley: Hoboken, NJ, USA, 1986; ISBN 978-0-471-08467-9.

60. Sirotin, I.S.; Bilichenko, Y.V.; Brigadnov, K.A.; Kireev, V.V.; Suraeva, O.V.; Borisov, R.S. Oligomeric hydroxy-aryloxy phosphazene based on cyclic chlorophosphazenes. Russ. J. Appl. Chem. 2013, 86, 1903-1912. [CrossRef]

61. Simonov-Emel'yanov, I.D.; Apeksimov, N.V.; Kochergina, L.M.; Bilichenko, Y.V.; Kireev, V.V.; Brigadnov, K.A.; Sirotin, I.S.; Filatov, S.N. Rheological and rheokinetic properties of phosphazene-containing epoxy oligomers. Polym. Sci. Ser. B 2016, 58, 168-172. [CrossRef]

62. Li, S.; Guan, W.; Wu, Z.; Lu, J.; Guo, J. An Improved Method to Determine Epoxy Index of Epoxy Resins. Polym.-Plast. Technol. Eng. 2007, 46, 901-903. [CrossRef]

(C) 2019 by the authors. Licensee MDPI, Basel, Switzerland. This article is an open access article distributed under the terms and conditions of the Creative Commons Attribution (CC BY) license (http://creativecommons.org/licenses/by/4.0/). 